
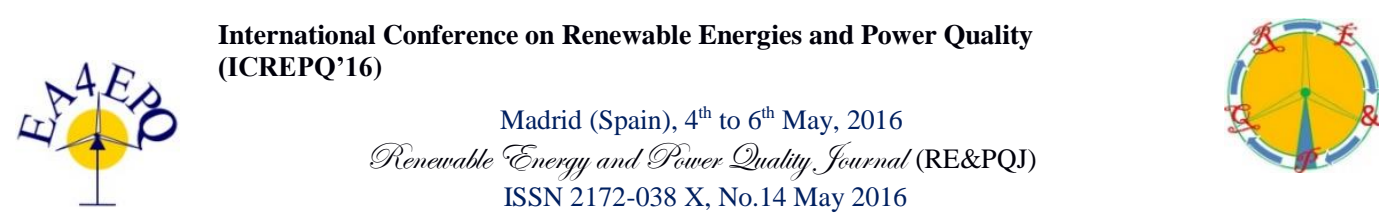

\title{
Study of the performance of an adiabatic cooling pad in an air cooler system
}

\author{
J. López ${ }^{1}$, F. Sánchez ${ }^{1}$, I. Arocas ${ }^{1}$, A. Viedma ${ }^{1}$, B. Zamora ${ }^{1}$, P. Martínez², M. Lucas² J. Ruiz² $^{2}$ M. Hernández ${ }^{1}$, \\ A. S. Káiser ${ }^{1 *}$ \\ ${ }^{1}$ Department of Thermal and Fluids Engineering \\ E.T.S.I.I., Polytechnic University of Cartagena \\ Campus La Muralla, 30202 Cartagena (Spain) \\ e-mail: antonio.kaiser@upct.es, javierlopeznu@ hotmail.com \\ ${ }^{2}$ Department of Mechanic Engineering and Energy \\ Miguel Hernández University \\ 03202 Elche (Spain)
}

\begin{abstract}
Adiabatic cooling pads are mostly used as a previous step for cooling systems, they cause the raise of the cooling system global efficiency. In this study, several types of pads have been analysed regarding on its compactness and thickness. The problem is addressed from an experimental, analytical and numerical point of view..
\end{abstract}

The validation of the temperature drop and cooling efficiency of the cooling pad numerical model is the main objective of this paper, and, in order to get this goal, Discrete Phase Model (DPM) of ANSYS Fluent software is used to calculate how water droplets, injected over the pad to cool the air, evaporate and how the continuous phase affect them.

The results of this paper, focused to be a part of a complete cooling system analysis carried out by the research group, show the performance of an adiabatic cooling pad varying its width and compactness.

\section{Key words}

Computational Fluid Dynamics (CFD), Evaporation, Experimental, Analytics, Discrete Phase Model (DPM)

\section{Introduction}

Energy consumption in refrigeration is one of the most important in every building, moreover, climate change is actually causing hotter summers and milder winters, so this consumption will be raising in the future. This study is a consequence of this, looking for an improvement in cooling efficiency to reduce the spending in electric energy [1], [2].

The use of water spray is increasing in evaporative cooling applications due to its efficiency and environmental respect. In the case of study, water is sprayed over the plastic pad in order to wet it forming water films over the material, this way, a crossing air stream evaporates a small part of the water and the air temperature descend as a consequence of it.

The experimental setup (Figures 1 and 2) consists on a prismatic plastic enclosure containing the elements of the system: the sprayer, placed at the top; the cooling pad; and a tank placed at the bottom to collect the sprayed water. Water is recirculated through the system so that the water flow stay constant all along the tests.

Regarding on the analytic model, the Liao Method [3] is used to determine the cooling efficiency and the temperature drop of the pad.

This Method allow us calculate the cooling efficiency through the Number of Transfer Units (NTU) which depends on the pad geometry and the air variables.

On the other hand, different numerical models have been studied. First of all, a real shape model was develop (Figure 3 ). This model presents a complex geometry which needs a great computational effort to be simulated. In order to simplify the problem, a porous media model was tried, however, water droplets do not impact anywhere in the domain and all droplets were drifted by the air stream.

Finally, a simplified geometry (Figure 4) was develop taking into account the compactness of each pad (Table 3 ). This model allows the simulation of a number of cases varying the required parameters without the great computational cost needed by the real geometry model.

In the following points, a description of the experimental setup is developed, also experimental tests, analytical model and numerical model are described. Finally, results for model validation and some conclusions are shown. 


\section{Experimental setup}

The experimental prototype consists on an air cooler with adiabatic pre-cooling. It is made-up by three main parts: air cooler, coupling and adiabatic cooling pad (Figures 1 and 2).

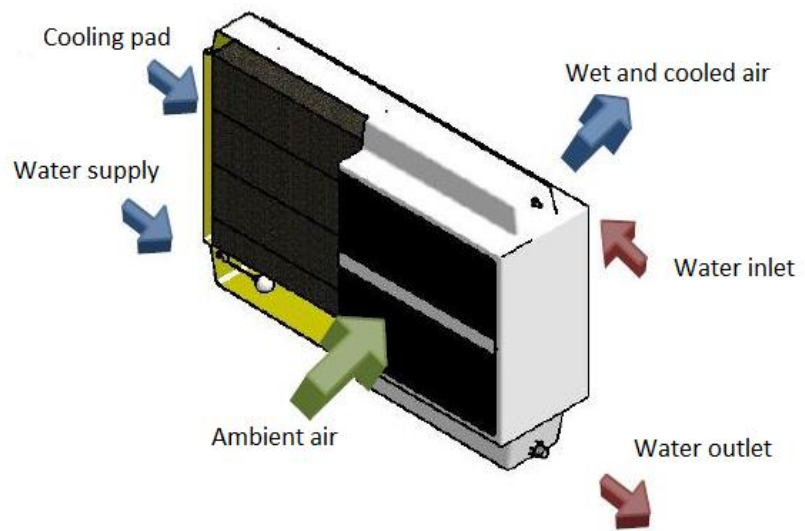

Figure 1. Experimental setup of the adiabatic cooling pad.

This study is focused on the adiabatic cooling pad, this element is used to reduce the air dry temperature by making air pass through the wetted pad in order to prevent water drops to be drifted over the air cooler, which may be environmental and healthy harmful.

Water drops are injected over the cooling pad through a set of sprayers placed at the top of the structure. These drops fall over the pad, which distributes the water through the whole area to maximize the contact between air and water. Finally, water is collected in a tank, connected to a pump, placed at the bottom of the structure to reenter the circuit. This way, all the water is recirculated in spite of a small part of it, which evaporates due to the air stream. Besides this, water temperature is considered constant all over the system. Water is recirculated through the system and, in a steady state, water will reach air inlet wet bulb temperature.

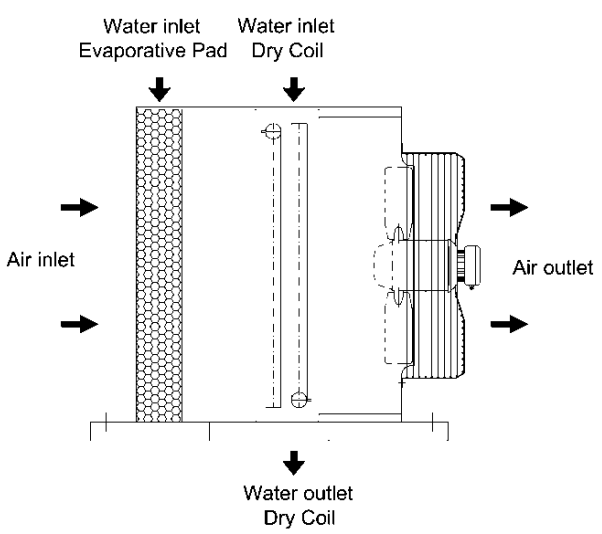

Figure 2. Scheme of functioning of the complete experimental setup with the studied adiabatic cooling pad.

The cooling pad have a $1000 \times 2000 \mathrm{~mm}$ frontal area. The width of the pad is one of the studied variables, with three different lengths: 80, 160 and $250 \mathrm{~mm}$. Moreover three different types of pad are used for the tests varying the compactness value.

Besides this, several measurements have to be done to characterize the system. The adiabatic cooling pad needs measurements for dry and wet bulb temperature, air velocity and water flow rate.

To determine air temperature at the inlet and outlet sections of the cooling pad, RTD sensors are used. Moreover, wet bulb temperature is determined through a hygrometer at the inlet section. On the other hand, air velocity is measured with a vane-type anemometer. And finally, water flow rate is determined by an electromagnetic flow meter.

\begin{tabular}{|c|c|c|c|c|}
\hline Variable & Sensor & Range & Accuracy & $\begin{array}{c}\text { Output } \\
\text { signal }\end{array}$ \\
\hline Air Temp. & Capacitive sensor & $-20^{\circ} \mathrm{C}$ to $80^{\circ} \mathrm{C}$ & $\pm 0,3^{\circ} \mathrm{C}$ & $4-20 \mathrm{~mA}$ \\
\hline Air humidity & Capacitive sensor & $0 \%$ to $100 \%$ & $\pm 2 \%$ & $4-20 \mathrm{~mA}$ \\
\hline Air velocity & $\begin{array}{c}\text { Vane type } \\
\text { anemometer }\end{array}$ & 0,5 to $20 \mathrm{~m} / \mathrm{s}$ & $\begin{array}{c}0,1 \mathrm{~m} / \mathrm{s} \\
\pm 1,5 \%\end{array}$ & $5-10 \mathrm{mV}$ \\
\hline $\begin{array}{c}\text { Water flow } \\
\text { rate }\end{array}$ & $\begin{array}{c}\text { Electromagnetic } \\
\text { flow meter }\end{array}$ & 0,5 to $21 \mathrm{~m} / \mathrm{s}$ & $\pm 0,3 \%$ & $5-10 \mathrm{mV}$ \\
\hline $\begin{array}{c}\text { Water } \\
\text { Temperature }\end{array}$ & RTD & $\begin{array}{c}-200^{\circ} \mathrm{C} \text { to } \\
600^{\circ} \mathrm{C}\end{array}$ & $\pm 0,05^{\circ} \mathrm{C}$ & Direct \\
\hline
\end{tabular}

\section{Mathematical formulation}

The model developed by $\mathrm{Wu}$ et al. [4] describes how to calculate cooling efficiency and outlet temperature in the evaporative cooling pad. Cooling efficiency equation depends on two experimental parameters for each case; these parameters must be experimentally obtained as long as they are affected by several variables such as pad geometry, inlet air velocity, water flow rate or air wet bulb temperature. Another analytical model is developed by Liao et al. [3]. However, this Liao model is less accurate due to the utilization of one pair of experimental parameters for all cases, in spite of the Wu model, which uses one pair of parameters for each case, as determined Igual Blasco [5].

Equation 1 is obtained from the energy conservation equation, the humid air enthalpy definition; and also from the equality of the convective energy transferred from water to air and the latent energy needed to evaporate water; considering water temperature and flow rate constant.

$$
\eta=1-e^{-N T U}=\frac{T_{1}-T_{2}}{T_{1}-T_{b h}}
$$

Cooling efficiency is defined as the rate between the actual cooling and the maximum possible cooling, given by the saturated air temperature (Equation 1). Where the Number of Transfer Units is:

$$
\mathrm{NTU}=\frac{\mathrm{h}_{\mathrm{D}} \cdot \mathrm{A}_{\mathrm{V}} \cdot \mathrm{dV}}{\mathrm{m}_{\mathrm{a}}}
$$

$\mathrm{Wu}$, in his study, finally determined the expression:

$$
\eta_{w}=1-e^{\frac{-h_{c} \cdot \xi \cdot \delta}{V \cdot \rho_{a} \cdot c_{p}}}
$$


Where $h_{c}$ is the convective heat transfer coefficient; $\xi$ is the pad compactness; $\delta$ is the pad width; $\mathrm{V}_{\mathrm{a}}$ is the air inlet velocity; $\rho_{a}$ is the air density and $C_{p}$ is the specific humid air heat.

Moreover, $\mathrm{h}_{\mathrm{c}}$ can be calculated in a turbulent regime as:

$$
h_{c}=\gamma \cdot R e^{4 / 5} \cdot P r^{1 / 3}
$$

This way, cooling efficiency can be defined as:

$$
\eta_{w}=1-e^{-\left(\frac{\beta \cdot \delta}{V^{\alpha}}\right)}
$$

Where $\beta$ includes air and material properties and pad characteristics, and it is almost constant for each pad despite important temperature changes.

\begin{tabular}{|c|c|c|c|}
\hline & & $\alpha$ & $\beta \delta$ \\
\hline \multirow{4}{*}{ Pad 1} & $20 \mathrm{~Hz}$ & \multirow{3}{*}{$-0,16$} & \multirow{3}{*}{0,87838513} \\
\hline & $30 \mathrm{~Hz}$ & & \\
\hline & $40 \mathrm{~Hz}$ & & \\
\hline & $50 \mathrm{~Hz}$ & 1,3 & 2,13211817 \\
\hline \multirow{4}{*}{ Pad 2} & $20 \mathrm{~Hz}$ & \multirow{3}{*}{$-0,22$} & \multirow{3}{*}{0,93733236} \\
\hline & $30 \mathrm{~Hz}$ & & \\
\hline & $40 \mathrm{~Hz}$ & & \\
\hline & $50 \mathrm{~Hz}$ & 0,41 & 1,31118073 \\
\hline \multirow{4}{*}{ Pad 3} & $20 \mathrm{~Hz}$ & \multirow{3}{*}{$-0,18$} & \multirow{3}{*}{1,06230068} \\
\hline & $30 \mathrm{~Hz}$ & & \\
\hline & $40 \mathrm{~Hz}$ & & \\
\hline & $50 \mathrm{~Hz}$ & 0,2 & 1,22567125 \\
\hline
\end{tabular}

Table 1.Parameters for analytical model in every tested case.

Finally, once cooling efficiency is calculated, air temperature at the outlet section can be determined from the expression above:

$$
T_{2}=T_{1}-\eta_{w} \cdot\left(T_{1}-T_{b h}\right)
$$

\section{Numerical model}

\section{A. Computational domain and meshes}

There are three different types of computational model: the first one is the more accurate modeling of the real geometry, the second one consists on a porous media, and the last one is a simplification of the first model.

First of all, a numerical model equal to the real geometry of the cooling pad is carried out. As seen on figure 3, the geometry complexity causes the need of a huge number of elements to do a proper simulation, as a consequence, the domain is reduced to simulate just a small part of the pad: a $50 \times 50 \times \xi(\mathrm{mm})$ prismatic domain. A non-structured mesh is used in this type of geometry, with 3,225,000 elements for $80 \mathrm{~mm}$ width case.
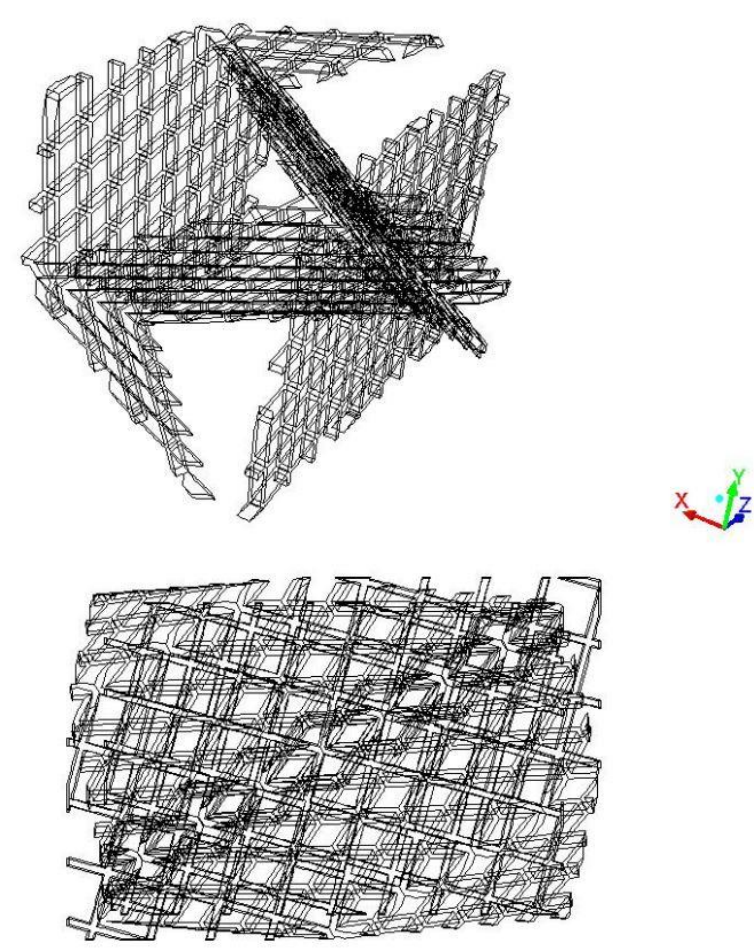

Figure 3. Real geometry numerical model.

The porous model is developed in order to simplify the problem as much as possible, this way, the geometry is easily created and meshed and the solution is quickly obtained. Moreover, the whole size geometry is represented with this type of model: a $2000 \times 1000 \times \xi(\mathrm{mm})$ domain. In order to set the characteristic porous media parameters, several simulations have been carried out comparing with experimental data, obtaining an optimal value for viscous resistance of $3.77 \cdot 10^{6} \mathrm{~m}^{-2}$.

As final alternative, a simplified model is developed taking into account the global pad compactness. This geometry is formed by parallel cylindrical tubes; these tubes are placed inside the domain considering the real geometry distances for each type of cooling pad. This model is meshed with structure prismatic elements, making possible the reduction of the computational cost, resulting in 250,000 elements for the $80 \mathrm{~mm}$ width case.

\section{B. Features of the model}

All simulations have been carried out with the same solving methods and characteristics. The standard k- $\varepsilon$ turbulence model is chosen; moreover, energy equation is activated, also species transport and the discrete phase. DPM (Discrete Particle Modeling) [6] is used to solve the problem: water droplets are injected at the top of the region, similar to the real sprayer in the experimental setup, then water droplets interact with the continuous phase and the 
cooling pad tubes, resulting in the cooling of the air stream and the impact of droplets over the pad.
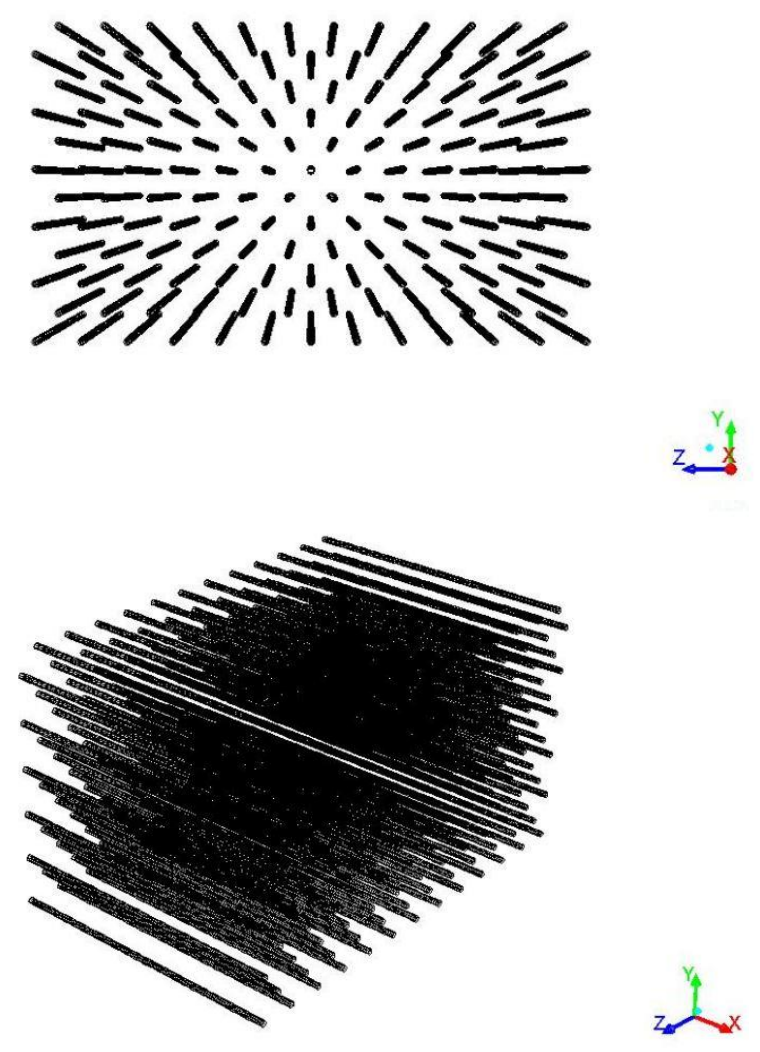

Figure 4. Simplified geometry numerical model.

\section{Boundary conditions}

Air inlet boundary condition is used to set the air velocity inlet at the entrance section of the cooling pad, this type of condition give the possibility to also set air temperature and humidity in this section. Wall boundary condition is set at the solid tubes inside the domain, in order to model the water film formed over the tubes once they are wetted, the water film option is enabled. Moreover, the temperature over the solid surface of the tubes is considered constant due to the fact that tubes are wetted and this water temperature remains constant at air wet bulb temperature.

Other boundary conditions are: symmetry, for lateral faces; outflow, for air outlet section; and wall, for top and bottom sections, in this case, the escape option is enabled in order to let water droplets escape the domain through these surfaces.

\section{Results and discussion}

Several cases have been analyzed to determine the proper operating conditions of the cooling pad, regarding on air velocity, cooling pad thickness and compactness, to determine their influence on cooling efficiency.

First of all, experimental tests were carried out for three different pad types: R1, R2 and R3 with different compactness values: $117.2,140.6$ and $234.4 \mathrm{~m}^{2} / \mathrm{m}^{3}$; three different pad thicknesses: 80, 160 and $250 \mathrm{~mm}$; and four air velocity values.

Air temperature at the outlet section is obtained from these tests, also air temperature at the inlet section and relative humidity are measured for each case. With this data, cooling efficiency is calculated throughout equation (1).

Table 2. Cooling efficiency and outlet air temperature comparison.

\begin{tabular}{|c|c|c|c|c|c|c|c|c|c|}
\hline \multicolumn{4}{|c|}{ Case } & \multicolumn{2}{|c|}{ Experimental } & \multicolumn{2}{|c|}{ Numerical } & \multicolumn{2}{|c|}{ Analytics } \\
\hline Width & Pad & Hz vent & Airvel. & Temp. D & Effic & Temp. D & Effic & Temp. D & Effic \\
\hline$(\mathrm{mm})$ & $\mathrm{ddu}$ & na vemi & $\mathrm{m} / \mathrm{s}$ & $(\mathrm{K})$ & (\%) & (K) & (\%) & (K) & (\%) \\
\hline \multirow{12}{*}{250} & \multirow{4}{*}{ R1 } & 20 & 1,02 & 4,9 & $59 \%$ & 4,1 & $49 \%$ & 4,8 & $59 \%$ \\
\hline & & 30 & 1,47 & 4,8 & $60 \%$ & 5,4 & $68 \%$ & 4,9 & $61 \%$ \\
\hline & & 40 & 1,82 & 5,1 & $62 \%$ & 5,3 & $65 \%$ & 5,1 & $62 \%$ \\
\hline & & 50 & 1,93 & 4,9 & $60 \%$ & 5,2 & $63 \%$ & 4,8 & $60 \%$ \\
\hline & \multirow{4}{*}{ R2 } & 20 & 1,10 & 4,8 & $62 \%$ & 4,8 & $71 \%$ & 4,8 & $62 \%$ \\
\hline & & 30 & 1,34 & 4,3 & $63 \%$ & 4,4 & $69 \%$ & 4,3 & $63 \%$ \\
\hline & & 40 & 1,71 & 4,8 & $65 \%$ & 5,1 & $69 \%$ & 4,8 & $65 \%$ \\
\hline & & 50 & 1,90 & 4,8 & $63 \%$ & 5,6 & $73 \%$ & 4,8 & $63 \%$ \\
\hline & \multirow{4}{*}{ R3 } & 20 & 0,62 & 4,2 & $62 \%$ & 4,8 & $71 \%$ & 4,2 & $62 \%$ \\
\hline & & 30 & 1,09 & 4,2 & $66 \%$ & 4,4 & $69 \%$ & 4,2 & $66 \%$ \\
\hline & & 40 & 1,44 & 4,3 & $66 \%$ & 4,5 & $69 \%$ & 4,5 & $68 \%$ \\
\hline & & 50 & 1,71 & 4,9 & $67 \%$ & 5,2 & $72 \%$ & 4,9 & $67 \%$ \\
\hline \multirow{12}{*}{160} & \multirow{4}{*}{ R1 } & 20 & 1,01 & 4,8 & $47 \%$ & 5,3 & $52 \%$ & 4,8 & $47 \%$ \\
\hline & & 30 & 1,63 & 4,8 & $55 \%$ & 4,9 & $56 \%$ & 5,0 & $57 \%$ \\
\hline & & 40 & 1,90 & 4,8 & $61 \%$ & 4,3 & $55 \%$ & 4,7 & $60 \%$ \\
\hline & & 50 & 1,96 & 4,8 & $54 \%$ & 5,2 & $58 \%$ & 4,8 & $54 \%$ \\
\hline & \multirow{4}{*}{ R2 } & 20 & 1,15 & 4,4 & $60 \%$ & 4,6 & $63 \%$ & 4,4 & $60 \%$ \\
\hline & & 30 & 1,43 & 4,4 & $61 \%$ & 4,6 & $64 \%$ & 4,4 & $61 \%$ \\
\hline & & 40 & 1,74 & 4,3 & $62 \%$ & 4,7 & $68 \%$ & 4,3 & $62 \%$ \\
\hline & & 50 & 2,00 & 4,3 & $61 \%$ & 4,8 & $69 \%$ & 4,3 & $61 \%$ \\
\hline & \multirow{4}{*}{ R3 } & 20 & 0,72 & 4,9 & $61 \%$ & 5,4 & $68 \%$ & 4,9 & $61 \%$ \\
\hline & & 30 & 1,36 & 4,3 & $65 \%$ & 4,4 & $67 \%$ & 4,3 & $64 \%$ \\
\hline & & 40 & 1,63 & 4,4 & $65 \%$ & 4,8 & $70 \%$ & 4,5 & $65 \%$ \\
\hline & & 50 & 1,81 & 4,5 & $63 \%$ & 4,8 & $67 \%$ & 4,5 & $63 \%$ \\
\hline \multirow{12}{*}{80} & \multirow{4}{*}{ R1 } & 20 & 1,07 & 4,9 & $40 \%$ & 5,4 & $44 \%$ & 4,2 & $34 \%$ \\
\hline & & 30 & 1,73 & 4,9 & $43 \%$ & 4,4 & $39 \%$ & 5,5 & $49 \%$ \\
\hline & & 40 & 2,04 & 4,8 & $55 \%$ & 4,2 & $48 \%$ & 4,7 & $54 \%$ \\
\hline & & 50 & 2,16 & 4,8 & $51 \%$ & 4,4 & $48 \%$ & 4,8 & $51 \%$ \\
\hline & \multirow{4}{*}{ R2 } & 20 & 1,24 & 4,5 & $56 \%$ & 4,5 & $56 \%$ & 4,5 & $57 \%$ \\
\hline & & 30 & 1,48 & 4,3 & $59 \%$ & 4,6 & $63 \%$ & 4,3 & $59 \%$ \\
\hline & & 40 & 1,82 & 4,4 & $61 \%$ & 4,7 & $65 \%$ & 4,4 & $61 \%$ \\
\hline & & 50 & 2,16 & 4,8 & $60 \%$ & 4,4 & $55 \%$ & 4,8 & $60 \%$ \\
\hline & \multirow{4}{*}{ R3 } & 20 & 1,01 & 4,4 & $59 \%$ & 4,8 & $66 \%$ & 4,4 & $59 \%$ \\
\hline & & 30 & 1,46 & 4,3 & $61 \%$ & 4,7 & $66 \%$ & 4,3 & $61 \%$ \\
\hline & & 40 & 1,82 & 5,1 & $62 \%$ & 4,7 & $58 \%$ & 5,1 & $62 \%$ \\
\hline & & 50 & 1,92 & 4,2 & $60 \%$ & 4,5 & $63 \%$ & 4,2 & $60 \%$ \\
\hline
\end{tabular}

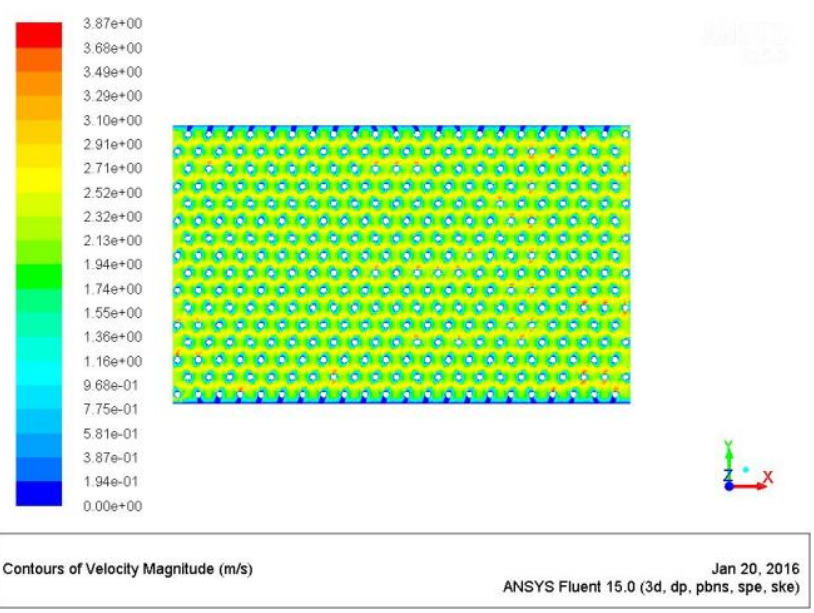

Figure 5. Air velocity contour for numerical model validation. 
Once experimental data was obtained, it could be used to validate both analytical and computational models. All experimental cases were analytically and computationally solved, calculating outlet air temperature and cooling efficiency. Numerical simulations carried out to study the problem were done with the simplified computational geometry. Before that, an experimental validation of air velocities and pressure drops was done. This way the problem of huge computational costs caused by the real geometry model, is avoided.
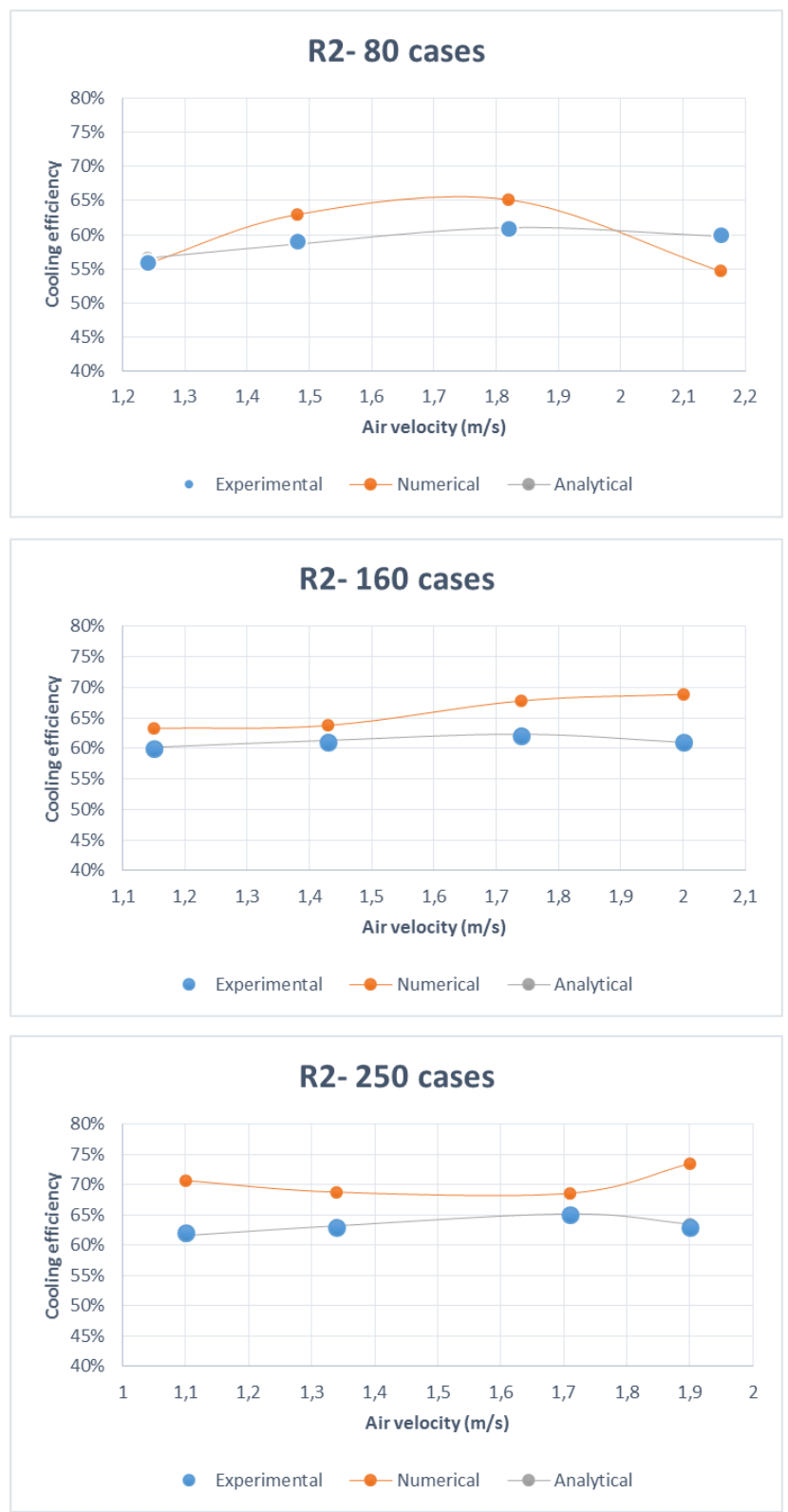

Figure 6. Comparison between experimental, analytical and numerical results of cooling efficiency as a function of air velocity.

A comparison between experimental, analytical and numerical results is shown in figures 6 and 7 .

Analytical results show a great agreement with experimental data in most cases, the mean error in outlet air temperature is lower than $1.5 \%$, and on the other hand, the numerical model shows a mean error lower than $8 \%$.
Attending to the trends in the figure 6 , as a function of air velocity, it can be seen that cooling efficiency raises when air velocity is increased, however, it reaches a maximum in all the studied cases and start decreasing. This optimum point is due to the balance between convective heat transfer and residence time. Moreover, air velocity increasing causes the undesirable phenomenon detachment of droplets from the cooling pad to the air cooler.
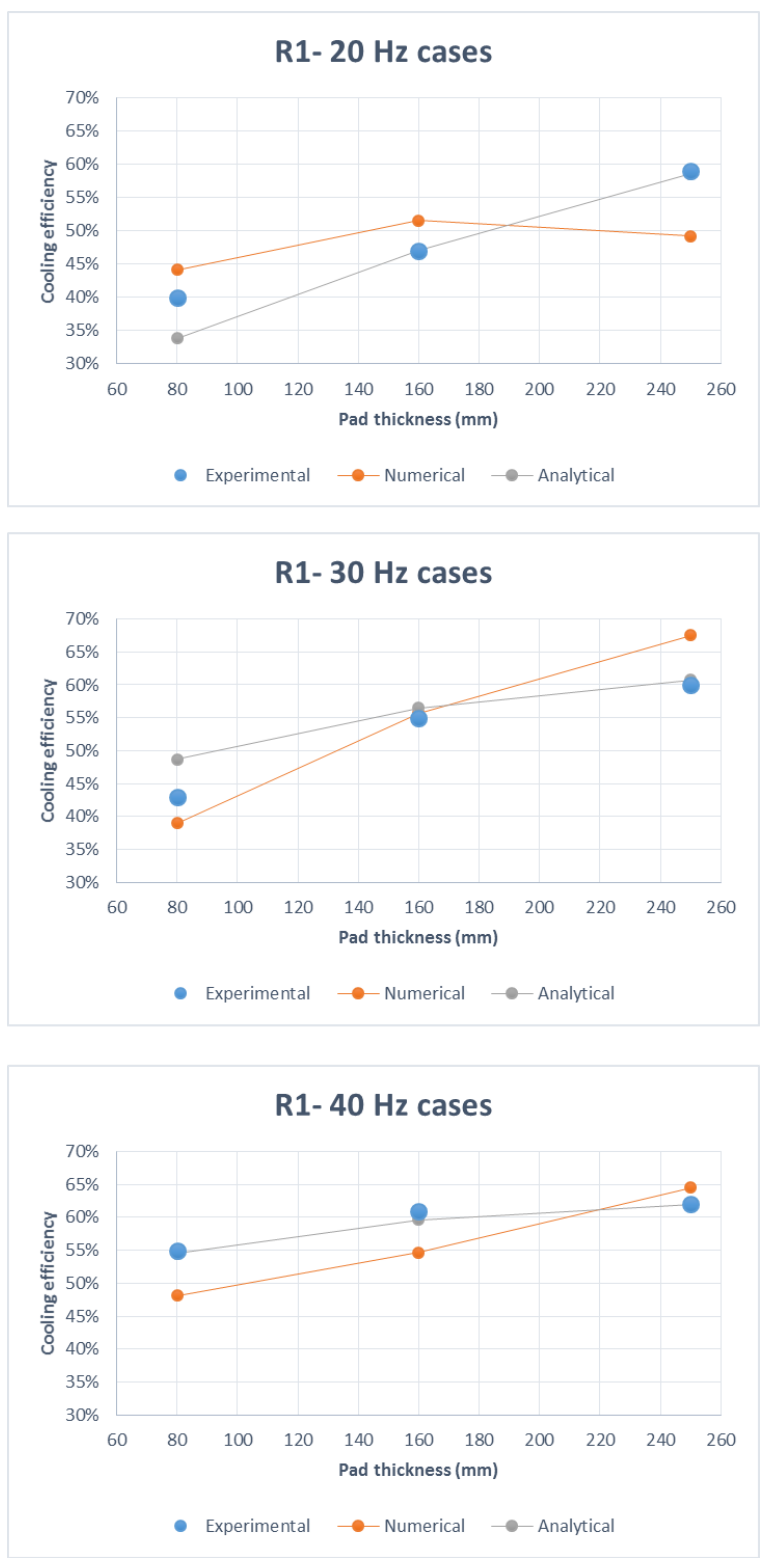

Figure 7.Comparison between experimental, analytical and numerical results of cooling efficiency as a function of air velocity.

Regarding on the cooling efficiency trends as a function of pad thickness, figure 7 shows that cooling efficiency is higher when the cooling pad is thicker, limited by the air wet bulb temperature. However, the pad thickness increasing also causes a higher vent power consumption as long as there is a higher pressure drop in the system. Sanchís Agulló [7] determined in his work, an optimal value for pad thickness in order to maximize the global efficiency of the global setup including the present adiabatic precooling and a downstream air cooler. 


\section{Conclusions}

In this work, the operating conditions of an adiabatic precooling are characterized. Experimental test have been carried out in order to get this goal and to validate both analytical and computational models. The results obtained from these models are properly validated with the experimental data as long as the mean air temperature error calculated is $1.5 \%$ in the analytical and $8 \%$ in the numerical model.

Regarding on the results shown in graphics some relevant conclusions may be highlighted. Cooling efficiency in adiabatic cooling pad depends on air velocity and pad geometry.

The increase of air velocity causes an optimum operating point balancing convective heat transfer and air residence time. On the other hand, the increase of the cooling pad thickness causes the increase of cooling efficiency until outlet air temperature reaches air wet bulb temperature.

As a resume, the simplified numerical model developed in this study offers the possibility of solving a complex problem, such as the interaction between an air stream and a cloud of sprayed droplets, in a few minutes, other way, this problem could not be solved nowadays due to the huge computational effort necessary to model the real geometry of cooling pad.

This type of simplified models may be useful in order to improve systems including cooling pads as long as the designer will have the possibility of testing multiple options without experimental tests just knowing the pad compactness and thickness.

One possible limitation of the numerical model may concern the size of the pad. Further simulations will be carried out with larger geometries to study the influence of the size of the domain in the results. However, a good agreement is shown in the results taking into account the calculated errors.

Analytical results meanwhile, show a minimum error in air temperature and cooling efficiency results. Nevertheless, the parameters $\alpha, \beta$ or $\delta$ needed to calculated the solution, are obtained through the experimental tests, and it is necessary to do more tests in order to solve the analytical model in a different range of boundary conditions, limitation not present in the numerical model.

\section{Acknowledgement}

The authors acknowledge the financial support received from the Spanish Government, through Projects ENE201348696-C2-1-R and C2-2-R as well as by the FEDER (Fondo Europeo de Desarrollo Regional).

\section{References}

[1] M. Lucas, P. J. Martínez, J. Ruiz, A. S. Kaiser, A. Viedma, B. Zamora, "The dry and adiabatic fluid cooler as an alternative to cooling towers: An experimental view", in $15^{\text {th }}$ Cooling tower and air-cooled heat exchanger conference, Beijing (2011).

[2] M.D. Pugh (CTI), Benefits of Water-Cooled Systems vs AirCooled Systems for Air-Conditioning Applications. AHR/ASHRAE/ARI Expo, 2005.

[3] C. Liao, K. Chiu, "Wind tunnel modeling the system performance of alternative evaporative cooling pads in Taiwan región”, in Building and Environment, 37, (2002), pp. 177-187.

[4] J. M. Wu, X. Huang, H. Zhang, "Theoretical analysis on heat and mass transfer in a direct evaporative cooler", in Applied Thermal Engineering, 29, (2009), pp. 980-984.

[5] A. Igual, "Optimización experimental del comportamiento térmico de un aero-refrigerador con pre-enfriamiento adiabático con diferentes espesores de relleno evaporativo", UMH, Elche, 2014.

[6] Fluent 14 Theory Guide, ANSYS.

[7] J. Sanchís, "Diseño y construcción de un prototipo de Sistema de climatización doméstico con un condensador híbrido empleando un pre-enfriamiento adiabático", UMH, Elche, 2015. 